\title{
Dynamics of Anomalous Temperature-Induced Emission Shift in MOCVD-grown (Al, In)GaN Thin Films
}

\author{
Yong-Hoon Cho ${ }^{1,3}$, G. H. Gainer ${ }^{1}$, J. B. Lam ${ }^{1}$, J. J. Song ${ }^{1}$, W, Yang ${ }^{2}$, and W. Jhe ${ }^{3}$ \\ ${ }^{1}$ Center for Laser and Photonics Research and Department of Physics \\ Oklahoma State University, Stillwater, OK 74078 \\ ${ }^{2}$ Honeywell Technology Center, 12001 State Highway 55, Plymouth, MN 55441 \\ ${ }^{3}$ Center for Near-field Atom-photon Technology and Department of Physics \\ Seoul National University, Seoul 151-742, Korea
}

\section{ABSTRACT}

We present a comprehensive study of the optical characteristics of (Al, In)GaN epilayers measured by photoluminescence (PL), integrated PL intensity, and timeresolved PL spectroscopy. For not only InGaN, but also AlGaN epilayers with large Al content, we observed an anomalous PL temperature dependence: (i) an "S-shaped" PL peak energy shift (decrease-increase-decrease) and (ii) an "inverted S-shaped" full width at half maximum (FWHM) change (increase-decrease-increase) with increasing temperature. Based on time-resolved PL, the S shape (inverted S shape) of the PL peak position (FWHM) as a function of temperature, and the much smaller PL intensity decrease in the temperature range showing the anomalous emission behavior, we conclude that strong localization of carriers occurs in InGaN and even in AlGaN with rather high $\mathrm{Al}$ content. We observed that the following increase with increasing $\mathrm{Al}$ content in AlGaN epilayers: (i) a Stokes shift between the PL peak energy and the absorption edge, (ii) a redshift of the emission with decay time, (iii) the deviations of the PL peak energy, FWHM, and PL intensity from their typical temperature dependence, and (iv) the corresponding temperature range of the anomalous emission behavior. This indicates that the band-gap fluctuation responsible for these characteristics is due to energy tail states caused by non-random inhomogeneous alloy potential variations enhanced with increasing $\mathrm{Al}$ content.

\section{INTRODUCTION}

Much interest has been focused on ( $\mathrm{Al}, \mathrm{In}) \mathrm{GaN}$ alloys and their heterostructures, because their band gap energy varies between 6.2 and $1.9 \mathrm{eV}$ at room temperature, and because of their potential applications such as red-ultraviolet (UV) light emitting devices $[1,2]$, solar-blind ultraviolet detectors [3], and high power and high temperature devices $[4,5]$. It has been demonstrated that InGaN-based light emitting devices are highly efficient and have very low thresholds, and it is believed that their recent success is deeply related to the role of carriers localized in the InGaN active region. For the InGaNbased light emitting device structures, In alloy inhomogeneity and/or quantum-dot-like In phase separation have been proposed as the origin of the localized states [6-10], and an anomalous temperature dependence of the InGaN emission peak energy due to band-tail states was observed [11-13].

However, according to recent thermodynamical calculations, ternary AlGaN alloys are predicted to not have an unstable mixing region, and hence, no phase separation is 
expected, in contrast to InGaN and InAlN alloys [14]. Although understanding the emission mechanism and the role of the energy tail states in ( $\mathrm{Al}, \mathrm{In}) \mathrm{GaN}$ alloys is very important for shorter wavelength light-emitting devices, the detailed emission properties of these materials have not been fully clarified. In this work, we report optical properties of $\mathrm{Al}_{\mathrm{x}} \mathrm{Ga}_{1-\mathrm{x}} \mathrm{N}$ epilayers $(\mathrm{x} \leq 0.6)$ in compare with $\mathrm{GaN}$ and $\mathrm{In}_{0.18} \mathrm{Ga}_{0.82} \mathrm{~N}$, as a function of temperature using photoluminescence (PL), integrated PL intensity, and time-resolved PL (TRPL).

\section{EXPERIMENT}

The $\mathrm{Al}_{\mathrm{x}} \mathrm{Ga}_{1-\mathrm{x}} \mathrm{N}$ thin films used in this study were grown by metalorganic chemical vapor deposition (MOCVD) on (0001) sapphire substrates. The samples were nominally identical aside from deliberate variations in the $\mathrm{Al}$ content $\mathrm{x}$ of the $\mathrm{Al}_{\mathrm{x}} \mathrm{Ga}_{1-\mathrm{x}} \mathrm{N}$ alloys, to investigate the influence of $\mathrm{x}$. The growth temperature was about $1050{ }^{\circ} \mathrm{C}$. Prior to $\mathrm{Al}_{\mathrm{x}} \mathrm{Ga}_{1-\mathrm{x}} \mathrm{N}$ growth, a thin $\sim 5$-nm-thick AlN buffer layer was deposited on the sapphire at a temperature of $625^{\circ} \mathrm{C}$. Triethylgallium, triethylaluminum, and ammonia were used as precursors in the $\mathrm{Al}_{\mathrm{x}} \mathrm{Ga}_{1-\mathrm{x}} \mathrm{N}$ growth. The $\mathrm{Al}_{\mathrm{x}} \mathrm{Ga}_{1-\mathrm{x}} \mathrm{N}$ layer thickness was about $1 \mu \mathrm{m}$. To evaluate the $\mathrm{Al}$ alloy composition and to check for ordering effects, the samples were analyzed with high-resolution $\mathrm{x}$-ray diffraction (XRD) using $\mathrm{Cu} \mathrm{K} \alpha_{1}$ radiation. PL experiments were performed using the 244-nm line of an intracavity doubled cw $\mathrm{Ar}^{+}$ laser as an excitation source. TRPL measurements were carried out using a picosecond pulsed laser system consisting of a cavity-dumped dye laser synchronously pumped by a frequency-doubled modelocked Nd:YAG laser for sample excitation and a streak camera for detection.

\section{RESULTS AND DISCUSSION}

Figure 1 shows the PL peak energy position $\left(\mathrm{E}_{\mathrm{PL}}\right)$ as a function of temperature for $\mathrm{In}_{0.18} \mathrm{Ga}_{0.82} \mathrm{~N}$ [15], $\mathrm{GaN}$, and $\mathrm{Al}_{\mathrm{x}} \mathrm{Ga}_{1-\mathrm{x}} \mathrm{N}$ epilayers with $\mathrm{x}=0.17,0.26,0.33$, and 0.6. The temperature-dependent PL peak shift for the GaN layer was consistent with the wellknown energy gap shrinkage: $\mathrm{E}_{\mathrm{g}}(\mathrm{T})=\mathrm{E}_{\mathrm{g}}(0)-\alpha \mathrm{T}^{2} /(\beta+\mathrm{T})$, where $\mathrm{E}_{\mathrm{g}}(\mathrm{T})$ is the band-gap transition energy at a temperature $\mathrm{T}$, and $\alpha$ and $\beta$ are known as the Varshni thermal coefficients [16]. On the other hand, the PL emission from $\operatorname{In}_{0.18} \mathrm{Ga}_{0.82} \mathrm{~N}$ and $\mathrm{Al}_{\mathrm{x}} \mathrm{Ga}_{1-\mathrm{x}} \mathrm{N}$ with rather high $\mathrm{x}$ did not follow the typical temperature dependence of the energy gap shrinkage. Instead, these ternary alloys clearly showed the "S-shaped" emission shift [initial redshift (region I), blueshift (region II), and final redshift (region III)] with increasing temperature] behavior, which is not seen in random homogeneous III-V alloys. For the $\mathrm{Al}_{\mathrm{x}} \mathrm{Ga}_{1-\mathrm{x}} \mathrm{N}$ epilayer with $\mathrm{x}=0.17(0.26,0.33,0.6)$, with increasing temperature up to $\mathrm{T}_{\mathrm{I}}$, where $\mathrm{T}_{\mathrm{I}}$ is $\sim 20(50,90,150) \mathrm{K}$, an initial small decrease in $\mathrm{E}_{\mathrm{PL}}$ was observed, followed by an increase in $\mathrm{E}_{\mathrm{PL}}$ in the temperature range of $\mathrm{T}_{\mathrm{I}}-\mathrm{T}_{\mathrm{II}}$, where $\mathrm{T}_{\mathrm{II}}$ is $\sim 70(110$, $150,225) \mathrm{K}$, and finally, $\mathrm{E}_{\mathrm{PL}}$ decreased again as the temperature increased above $\mathrm{T}_{\mathrm{II}}$. This anomalous temperature-induced emission shift is very similar to the behavior previously observed in the $\mathrm{In}_{0.18} \mathrm{Ga}_{0.82} \mathrm{~N}$ epilayer $\left(\mathrm{T}_{\mathrm{I}}\right.$ and $\mathrm{T}_{\mathrm{II}}$ were $\sim 50 \mathrm{~K}$ and $\sim 110 \mathrm{~K}$, respectively, for the $\operatorname{In}_{0.18} \mathrm{Ga}_{0.82} \mathrm{~N}$ epilayer) [15], except that the amount of the redshift in region I of $\mathrm{In}_{0.18} \mathrm{Ga}_{0.82} \mathrm{~N}$ is larger than that of $\mathrm{Al}_{\mathrm{x}} \mathrm{Ga}_{1-\mathrm{x}} \mathrm{N}$ of comparable alloy content $\mathrm{x}$, possibly due to a different nature (or degree) of potential fluctuations. Note that the corresponding 


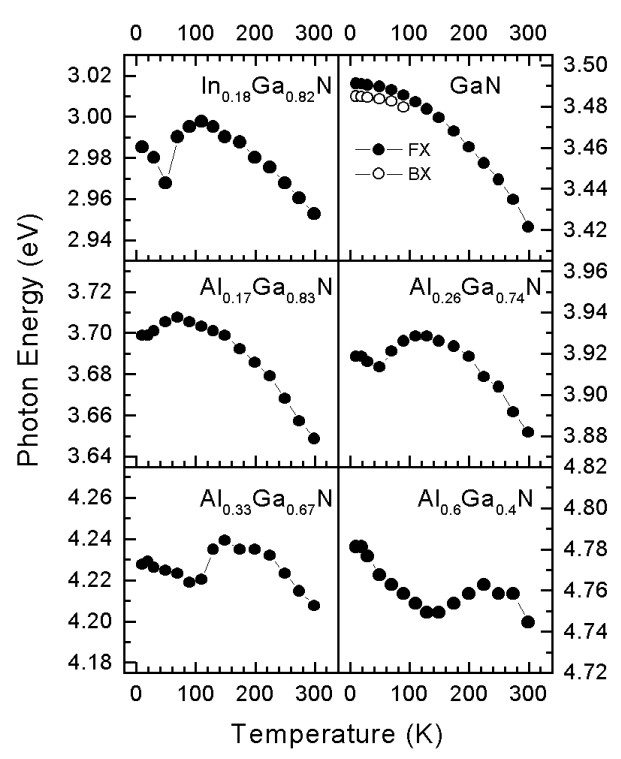

Figure 1. PL peak energy for $\mathrm{In}_{0.18} G a_{0.82} \mathrm{~N}$ [Ref. 15], GaN, and $A l_{x} G a_{1-x} N(x=0.17,0.26,0.33$, and $0.6)$ epilayers in the temperature range from 10 to $300 \mathrm{~K}$. The emission peaks from $\mathrm{In}_{0.18} G a_{0.82} \mathrm{~N}$ and $A l_{x} G a_{1-x} N$ clearly show an anomalous $S$-shaped shift with increasing temperature. The free exciton $(F X)$ and bound exciton (BX) curves are shown for GaN and follow the typical temperature dependence of the energy gap shrinkage.

temperature regions of the $\mathrm{Al}_{\mathrm{x}} \mathrm{Ga}_{1-\mathrm{x}} \mathrm{N}$ epilayers significantly depend on $\mathrm{x}$ : with increasing $\mathrm{x}$, the characteristic temperatures $\mathrm{T}_{\mathrm{I}}$ and $\mathrm{T}_{\mathrm{II}}$ increase and the temperature regions I and II are extended into higher temperatures. Another unusual property of the PL spectra for these ternary alloys is that the FWHM shows an anomalous "inverted S-shaped" FWHM broadening (increase-decrease-increase) behavior with increasing temperature $[15,17]$.

Figure 2 shows Arrhenius plots of the normalized integrated PL intensities $\left(\mathrm{I}_{\mathrm{PL}}\right)$ over the temperature range of $10-300 \mathrm{~K}$. The main difference between the $\mathrm{I}_{\mathrm{PL}}$ curves occurs in the temperature range showing the abnormal temperature dependence (i.e., regions I and II). An activation energy $\left(\mathrm{E}_{\mathrm{a}}\right)$ estimated from the relationship $\mathrm{I}_{\mathrm{PL}}=\mathrm{I}_{0} /[1+\mathrm{A}$ $\left.\exp \left(-E_{\mathrm{a}} / \mathrm{kT}\right)\right]$ in the transition region II corresponds to the magnitude of effective potential fluctuations. The activation energies are $9.6 \pm 1.5,21.2 \pm 1.2$, and $44.6 \pm 1.8 \mathrm{meV}$ for the $\mathrm{Al}_{\mathrm{x}} \mathrm{Ga}_{1-\mathrm{x}} \mathrm{N}$ epilayers with $\mathrm{x}=0.17,0.26$, and 0.33 , respectively, reflecting more effective confinement with increasing $\mathrm{x}$.

Figure 3 shows the temperature dependence of the TRPL lifetimes for the $\mathrm{Al}_{0.17} \mathrm{Ga}_{0.83} \mathrm{~N}$ and $\mathrm{Al}_{0.33} \mathrm{Ga}_{0.67} \mathrm{~N}$ thin films. The lifetimes were monitored at the peak energy (closed circles), lower energy side (open squares) and higher energy side (open triangles) of the PL peak position. For both samples, the measured lifetime increases with decreasing emission energy, and hence, the peak energy of the emission shifts to the low energy side as time proceeds. In temperature region I, the change in lifetime with temperature is very small and the difference between the lifetimes measured above, below, and at the peak energy is quite large, indicating that radiative recombination processes are dominant. As the temperature is further increased, the overall lifetime quickly decreases in region II and is almost constant in region III, reflecting a strong influence of non-radiative recombination processes. This is further evidenced by a quick 


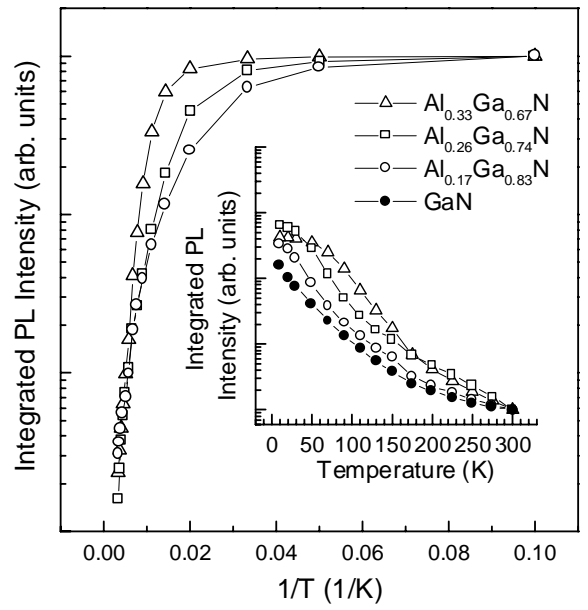

Figure 2. Normalized integrated PL intensity as a function of temperature for the AlGaN-related emission of $A l_{x} G a_{1-x} N$ epilayers with Al content $x=0,0.17,0.26$, and 0.33 .

decrease in the difference between lifetimes measured above, below, and at the peak energy in region II and no difference through region III. Using the relationship between the quantum efficiency $\eta(\mathrm{T})$ and the lifetime $\tau(\mathrm{T})$, we found that the transition from radiative to nonradiative recombination occurs at $\sim 30$ and $\sim 80 \mathrm{~K}$ for the $\mathrm{Al}_{0.17} \mathrm{Ga}_{0.83} \mathrm{~N}$ and $\mathrm{Al}_{0.33} \mathrm{Ga}_{0.67} \mathrm{~N}$ thin films, respectively. Consequently, radiative recombination is dominant in region $\mathrm{I}$, and the transition from radiative to nonradiative recombination occurs at about $\mathrm{T}_{\mathrm{I}}$, for both samples. In region II, in which a blueshift of the PL peak energy was observed, nonradiative recombination becomes dominant, so the lifetimes and their differences dramatically decrease. In region III, a typical temperature dependence of PL spectra was observed and no sudden change of lifetime occurs.

A similar anomalous temperature dependence for the PL peak energy was reported for ordered (Al)GaInP [18, 19] and disordered (Ga)AlAs/GaAs superlattices [20, 21]. Moreover, there have been some reports on the long-range ordering effect in molecular beam epitaxy-grown InGaN and AlGaN films [22]. To determine if ordered domains are in our $\mathrm{Al}_{\mathrm{x}} \mathrm{Ga}_{1-\mathrm{x}} \mathrm{N}$ alloys, XRD measurements were made. However, no (0001) XRD patterns were observed, indicating an absence of ordered domains in the $\mathrm{Al}_{\mathrm{x}} \mathrm{Ga}_{1-\mathrm{x}} \mathrm{N}$ alloys under investigation. Therefore, we rule out the possibility of the ordering effect in the $\mathrm{Al}_{\mathrm{x}} \mathrm{Ga}_{1-\mathrm{x}} \mathrm{N}$ alloys. This is quite surprising since the AlGaN ternary alloys investigated have neither ordering effects nor phase separations (according to theoretical prediction [14]), and most homogeneous ternary alloys do not show such an anomalous emission behavior. Therefore, we conclude that the anomalous emission is due to optical transitions from "localized" to "extended" band tail states, and that the band-gap fluctuation responsible for the anomalous behavior is enhanced with increasing $\mathrm{x}$ and can be attributed to energy tail states of inhomogeneous alloy fluctuations non-randomly distributed in the plane of the epilayers. 

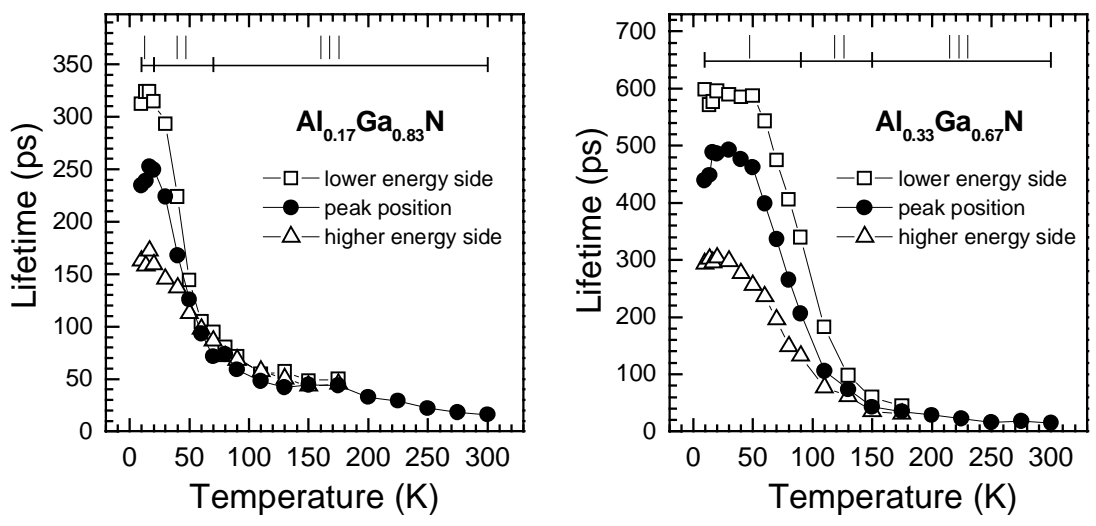

Figure 3. Lifetime as a function of temperature for the emission in $A l_{x} G a_{1-x} N$ epilayers with $x=0.17$ and 0.33. Note that the lower energy side of the PL peak has a longer lifetime than the higher energy side for $T<T_{I I}$, while there is no difference between lifetimes monitored above (open triangles), below (open squares), and at (closed circles) the peak energy for $T>T_{I I}$.

\section{CONCLUSIONS}

We investigated the optical characteristics of MOCVD-grown (Al, In)GaN epilayers by means of PL, integrated PL intensity, and TRPL. We observed anomalous temperature-induced PL emission behavior for $\operatorname{In}_{0.18} \mathrm{Ga}_{0.82} \mathrm{~N}$ and $\mathrm{Al}_{\mathrm{x}} \mathrm{Ga}_{1-\mathrm{x}} \mathrm{N}$ epilayers: an "S-shaped" PL peak energy shift (decrease-increase-decrease) and an "inverted Sshaped" PL FWHM broadening (increase-decrease-increase) with increasing temperature. From the integrated PL intensity and TRPL measurements as a function of temperature, we found that the anomalous temperature-induced emission shift is deeply related to thermal population in localized energy tail states of alloy potential inhomogeneities in the $\mathrm{Al}_{\mathrm{x}} \mathrm{Ga}_{1-\mathrm{x}} \mathrm{N}$ epilayers. The following characteristics increase with increasing $\mathrm{Al}$ content in the AlGaN epilayers: (i) a Stokes shift between the PL peak energy and the absorption edge, (ii) a redshift of the emission with decay time, (iii) the deviations of the PL peak energy, FWHM, and PL intensity from their typical temperature dependence, and (iv) the corresponding temperature range of the anomalous emission behavior. Therefore, we attribute the anomalous emission behavior to the enhanced band-gap fluctuation in $\mathrm{Al}_{\mathrm{x}} \mathrm{Ga}_{1-\mathrm{x}} \mathrm{N}$ epilayers caused by an inhomogeneous spatial distribution of the $\mathrm{Al}$ content, and the degree of band-gap fluctuation increases with increasing $\mathrm{x}$.

\section{ACKNOWLEDGMENTS}

The authors would like to acknowledge the contributions of Dr. Y. H. Kwon for the XRD measurements. This work was supported by AFOSR, ARO, ONR, DARPA, and CRI of MOST. 


\section{REFERENCES}

1. S. Nakamura, M. Senoh, N. Iwasa, S. Nagahama, T. Yamada, and T. Mukai, Jpn. J. Appl. Phys. Part 2 34, L1332 (1995).

2. S. Nakamura, M. Senoh, S. Nagahama, N. Iwasa, T. Yamada, T. Matsushita, Y. Sugimoto, and H. Kiyoku, Appl. Phys. Lett. 69, 4056 (1996).

3. B. W. Lim, Q. C. Chen, J. Y. Yang, and M. A. Khan, Appl. Phys. Lett. 68, 3761 (1996).

4. Y. F. Wu, B. P. Keller, S. Keller, D. Kapolnek, P. Kozodoy, S. P. DenBaars, and U. K. Mishra, Appl. Phys. Lett. 69, 1438 (1996).

5. X. H. Yang, T. J. Schmidt, W. Shan, J. J. Song, and B. Goldenberg, Appl. Phys. Lett. 66, 1 (1995).

6. S. Chichibu, T. Azuhata, T. Sota, and S. Nakamura, Appl. Phys. Lett. 69, 4188 (1996).

7. E. S. Jeon, V. Kozlov, Y. -K. Song, A. Vertikov, M. Kuball, A. V. Nurmikko, H. Liu, C. Chen, R. S. Kern, C. P. Kuo, and M. G. Craford, Appl. Phys. Lett. 69, 4194 (1996).

8. P. Perlin, V. Iota, B. A. Weinstein, P. Wiśniewski, T. Suski, P. G. Eliseev, and M. Osiński, Appl. Phys. Lett. 70, 2993 (1997).

9. Y. Narukawa, Y. Kawakami, M. Funato, Sz. Fujita, Sg. Fujita, and S. Nakamura, Appl. Phys. Lett. 70, 981 (1997).

10. Y. Narukawa, Y. Kawakami, Sz. Fujita, Sg. Fujita, and S. Nakamura, Phys. Rev. B 55, R1938 (1997).

11. Y. H. Cho, G. H. Gainer, A. J. Fischer, J. J. Song, S. Keller, U. K. Mishra, and S. P. DenBaars, Appl. Phys. Lett. 73, 1370 (1998).

12. P. G. Eliseev, P. Perlin, J. Lee, and M. Osiński, Appl. Phys. Lett. 71, 569 (1997).

13. K. G. Zolina, V. E. Kudryashov, A. N. Turkin, and A. E. Yunovich, MRS Internet J. Nitride Semicond. Res. 1, Art, 11 (1996).

14. T. Matsuoka, MRS Internet J. Nitride Semicond. Res. 3, 54 (1998).

15. Y. H. Cho, B. D. Little, G. H. Gainer, J. J. Song, S. Keller, U. K. Mishra, and S. P. DenBaars, MRS Internet J. Nitride Semicond. Res. 4S1, G2.4 (1999).

16. Y. P. Varshni, Physica 34, 149 (1967).

17. Y. H. Cho, G. H. Gainer, J. B. Lam, J. J. Song, W. Yang, and S. A. McPherson, Mat. Res. Soc. Symp. Proc. 572, 457 (1999).

18. F. A. J. M. Driessen, G. J. Bauhuis, S. M. Olsthoorn, and L. J. Giling, Phys. Rev. B 48, 7889 (1993).

19. K. Yamashita, T. Kita, H. Nakayama, and T. Nishino, Phys. Rev. B 55, 4411 (1997).

20. A. Chomette, B. Deveaud, A. Regreny, and G. Bastard, Phys. Rev. Lett. 57, 1464 (1986).

21. T. Yamamoto, M. Kasu, S. Noda, and A. Sasaki, J. Appl. Phys. 68, 5318 (1990).

22. D. Korakakis, K. F. Ludwig, Jr., and T. D. Moustakas, Appl. Phys. Lett. 71, 72 (1997). 